Check for updates

Cite this: RSC Adv., 2019, 9, 18498

\title{
Interaction of the synthetic antithrombotic peptide P10 with thrombin: a spectroscopy study
}

\author{
Fangyuan Chen, Han Jiang, Wenwei Chen and Guangrong Huang (iD) *
}

Thrombin is a critical serine protease in the coagulation system and is widely used as a target protein for antithrombotics. Spectroscopic analysis is a simple and effective method that is used to study the interaction between small molecules and proteins. In this study, the interactions of a potential antithrombotic peptide AGFAGDDAPR (P10) with thrombin were investigated by fluorescence spectroscopy, UV-vis spectroscopy, circular dichroism, Fourier-transform infrared spectroscopy and Raman spectroscopy, respectively. The results showed that the peptide P10 bonded to thrombin via hydrogen bonding and van der Waals forces, resulting in fluorescence quenching. And, the secondary structure of thrombin changed, the $\beta$-sheet decreased, and the random coil increased. The peptide P10 bonded to proline and lysine, and changed the space structure of thrombin, resulting in inhibition of thrombin activity. The results contributed to exploration of the mechanism of this potential antithrombotic drug interaction with thrombin in order to provide a preliminary understanding of the pharmacodynamic properties of P10.

Received 22nd April 2019

Accepted 29th May 2019

DOI: 10.1039/c9ra02994j

rsc.li/rsc-advances

isolated and identified from natural materials and have

\section{Introduction}

The coagulation process is a cascade of proteolytic reactions, divided into an intrinsic pathway and an extrinsic pathway. Although the cascade starts with two different mechanisms, its ultimate goal is to convert soluble fibrinogen to insoluble fibrin. Both pathways are combined at the activation step of thrombin in the cascade. ${ }^{1}$ Therefore, thrombin is considered as a critical serine protease in the blood coagulation process. ${ }^{2}$ In general, thrombin consists of a 36-residue light chain and a 259-residue heavy chain that can be mainly divided into the active site, exosite 1 and exosite 2 , which are the regions where thrombin exerts its coagulation function., ${ }^{3,4}$ The thrombin active site cutting fibrinogen into fibrin is located in the gap formed at the interface of the two barrels. ${ }^{5}$ The substrate recognition of thrombin is regulated by two external sites responsible for substrate turning and orientation in the protease catalytic site. Two exosites regulate the substrate recognition of thrombin, which are remote from the active site and responsible for substrate turning and orientation. ${ }^{6}$ Exosite 1 binds to the extracellular domain of fibrinogen, thrombomodulin and the type-1 protease-activated receptor on the platelet. Exosite 2 binds to $\beta 2$-glycoprotein-1 and determines the position of thrombin on the platelets by interacting with glycoprotein $\operatorname{Ib} \alpha$ receptors..$^{7-9}$

Peptides have attracted great interest in medical or health protection in the past few decades. Various peptides have been

Key Lab of Marine Food Quality and Hazard Controlling Technology of Zhejiang Province, College of Life Sciences, China Jiliang University, Hangzhou, China. E-mail: grhuang@126.com; Tel: +8657186875628 demonstrated many biologically active functions such as bacteriostatic, antioxidant, hypotensive, hypoglycemic, etc. ${ }^{10,11}$ Many naturally occurring antithrombotic biologically active peptides have been found to be specific inhibitors of thrombin. Typically, a 60-amino acid peptide purified from the extract of Ornithodoros moubata, ${ }^{12}$ a peptide called draculin isolated from the saliva of the Desmodus rotundus ${ }^{13}$ and AduNAP4 from the human hookworm ${ }^{14}$ have already displayed antithrombotic activity via interacting with thrombin. In particular, hirudin, a peptide with 65 or 66 amino acids extracted from leeches, has been widely studied as a highly effective direct thrombin inhibitor. ${ }^{6,15,16}$ Some peptides derived from organism proteins by enzymatic hydrolysis also exhibit antithrombotic activity, such as peptide FQSEEQQQTEDELQDK from casein hydrolysate. ${ }^{17}$ In particular, a peptide P10 (AGFAGDDAPR) isolated from Tenebrio molitor with enzymatic hydrolysate exhibited antithrombotic activity in our previous study.

Information about the binding between antithrombotic peptides and thrombin is the basis for understanding the pharmacodynamic properties of antithrombotic peptides. At present, studies on the interaction of antithrombotic peptides and thrombin mainly focus on methods of X-ray diffraction and molecular simulation..$^{18,19}$ But they have limitations in the understanding of molecular structure, function, and physical properties in solution which is required by the latest developments in protein structure research. Spectral methods that are not limited to the morphology of molecules have attracted great interest and have been used to effectively reveal the structure of proteins in solution..$^{20}$ In this work, the interaction between an antithrombotic peptide P10 and thrombin was studied by 
fluorescence spectroscopy and UV-vis absorption spectra. Circular dichroism (CD), Fourier-transform infrared spectroscopy (FT-IR) and Raman spectroscopy were used to analyze the effect of peptides on the thrombin structure. The mechanism of interaction of the peptide with the thrombin molecule is expected to be initially revealed. At the same time, it also aims to provide a comprehensive and detailed spectroscopic analysis method for revealing the interaction between small molecule ligands and macromolecular receptors.

\section{Results and discussion}

\section{The antithrombotic activity of the synthesized peptide P10}

The in vitro antithrombotic activity of P10 was measured quantitatively and the results are shown in Fig. 1A. The peptide concentration showed a dose-responsive behavior to the antithrombotic activity. These data were processed using the probit program in SPSS to give the $\mathrm{IC}_{50}=0.16 \mathrm{mg} \mathrm{mL}^{-1}$ (inhibition of $50 \%$ thrombus formation) (Fig. 1B). ${ }^{21}$ Ren et al. ${ }^{22}$ purified an anticoagulant peptide with the sequence VEPVTVNPHE from Buthus martensii Karsch, which inhibited thrombin activity with an $\mathrm{IC}_{50}$ of $0.012 \mathrm{mg} \mathrm{mL}^{-1}$. In addition, three peptides SWAQL, GNHEAGE and CFNEYE were purified from the Alcalase 2.4L hydrolysate of peanut protein, showing complete inhibition of thrombin activity at a concentration of $0.4 \mathrm{mg} \mathrm{mL}{ }^{-1} .^{23}$ However, the synthesized KNAENELGEVTVR illustrated $67.21 \%$ antithrombotic activity at a concentration of $1 \mathrm{mg} \mathrm{mL}{ }^{-1} \cdot{ }^{24}$ Although P10 had a low antithrombotic activity, it may reduce the probability of bleeding or other side effects. ${ }^{25}$

\section{Fluorescence quenching of thrombin by P10}

Fluorescence quenching. Fluorescence spectroscopy provides information on the structure and kinetics of the protein that is often used to study protein folding and binding reactions. ${ }^{26}$ The thrombin molecular structure contains 11 tyrosine residues, 11 phenylalanine residues and 8 tryptophan residues. The fluorescence intensity of tryptophan is greatest in these fluorescent chromogenic amino acids. When the excitation light is set to $280 \mathrm{~nm}$, it can be considered that the fluorescence exhibited by the protein is derived from the tryptophan in the molecule. ${ }^{27}$ Like most proteins, conformational changes,
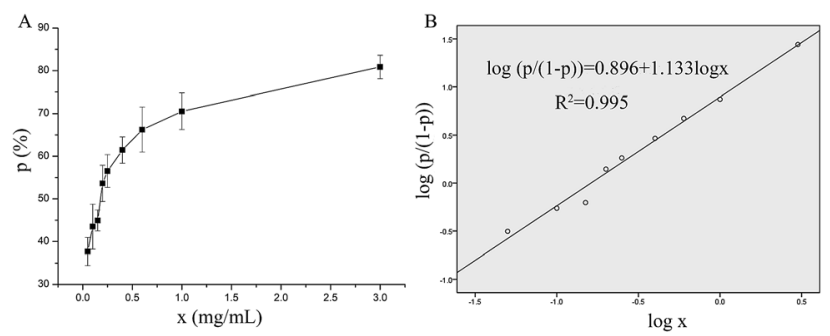

Fig. 1 The antithrombotic activity of P10. (A) A visual map of the relationship between $\mathrm{P} 10$ concentration and the inhibition rate of the thrombin. (B) The probit model for the logarithm of the inhibition rate of the thrombin and the P10 concentration. The $x$ represents the concentration of $\mathrm{P} 10$, and $p$ represents the inhibition rate of the thrombin (antithrombotic activity). subunit binding, substrate binding and denaturation can lead to changes in the intrinsic fluorescence of thrombin..$^{28}$ The effect of P10 on the fluorescence intensity of thrombin is shown in Fig. 2A. The excitation wavelength was fixed at $280 \mathrm{~nm}$, and thrombin had a strong fluorescence emission band at $331 \mathrm{~nm}$. The fluorescence emission peaks at $331 \mathrm{~nm}$ indicated that the tryptophan residues were the major contributing fluorophores in all three protein species. Obviously, the fluorescence intensity of thrombin reduced gradually with the P10 concentration, but the maximum emission wavelength and shape of the peak was not affected. This suggests that P10 might interact with thrombin and quench its intrinsic fluorescence. No spectral shift of the emission spectrum was observed in the P10 plus thrombin mixture, indicating that the hydrophobicity and polarity of the chromophore did not change. ${ }^{29}$

The quenching mechanism. The Stern-Volmer plot at $290 \mathrm{~K}$ and $310 \mathrm{~K}$ was plotted to determine the quenching mechanism (static quenching or dynamic quenching), as shown in Fig. 2B. $F_{0}$ and $F$ represented the fluorescence intensity of thrombin in the absence and presence of $\mathrm{P} 10$, respectively. And [Q] represented the concentration of the quencher. In general, the stability and quenching constants of the compounds formed under the static quenching mechanism decrease with increasing temperature. The interaction under dynamic quenching increases the number of effective collisions and enhances energy transfer, thus increasing the quenching constant of the fluorescent material as the temperature increases. ${ }^{26,30}$ The ratio of $F_{0} / F$ was linear with the concentration of P10, and the slope of the quenching curve at $290 \mathrm{~K}$ was higher than that at $310 \mathrm{~K}$ (Fig. 2B).

This indicated that fluorescence quenching between thrombin and P10 was static quenching.

To confirm this conclusion, the fluorescence quenching data was further analyzed by the Stern-Volmer eqn (1). ${ }^{31}$ Where $K_{\mathrm{sv}}$ represented the quenching constant of the Stern-Volmer.

$$
\frac{F_{0}}{F}=1+K_{\text {sv }}[\mathrm{Q}]
$$

By calculation, the values of $K_{\mathrm{sv}}$ were $2.35 \times 10^{3} \mathrm{M}^{-1}(290 \mathrm{~K})$ and $1.74 \times 10^{3} \mathrm{M}^{-1}(310 \mathrm{~K})$. Generally, the $K_{\mathrm{sv}}$ value decreases with the temperature increases, indicating static quenching. On the contrary, it indicates dynamic quenching. The results showed that the quenching process of thrombin by P10 accorded with the static quenching regular pattern.

The binding constants and the number of binding sites. The binding constant $\left(K_{\mathrm{b}}\right)$ and the number of binding sites $(n)$ can be obtained from eqn (2) when small molecules are independently bound to a set of equivalent sites on the macromolecule: ${ }^{33}$

$$
\log \frac{F_{0}-F}{F}=\log K_{\mathrm{b}}+n \log [\mathrm{Q}]
$$

The plot of the P10 plus thrombin complex at $290 \mathrm{~K}$ and 310 $\mathrm{K}$ is shown in Fig. $2 \mathrm{C}$, and the corresponding calculations are shown in Table 1. It was found that the $K_{\mathrm{b}}$ value decreased with 

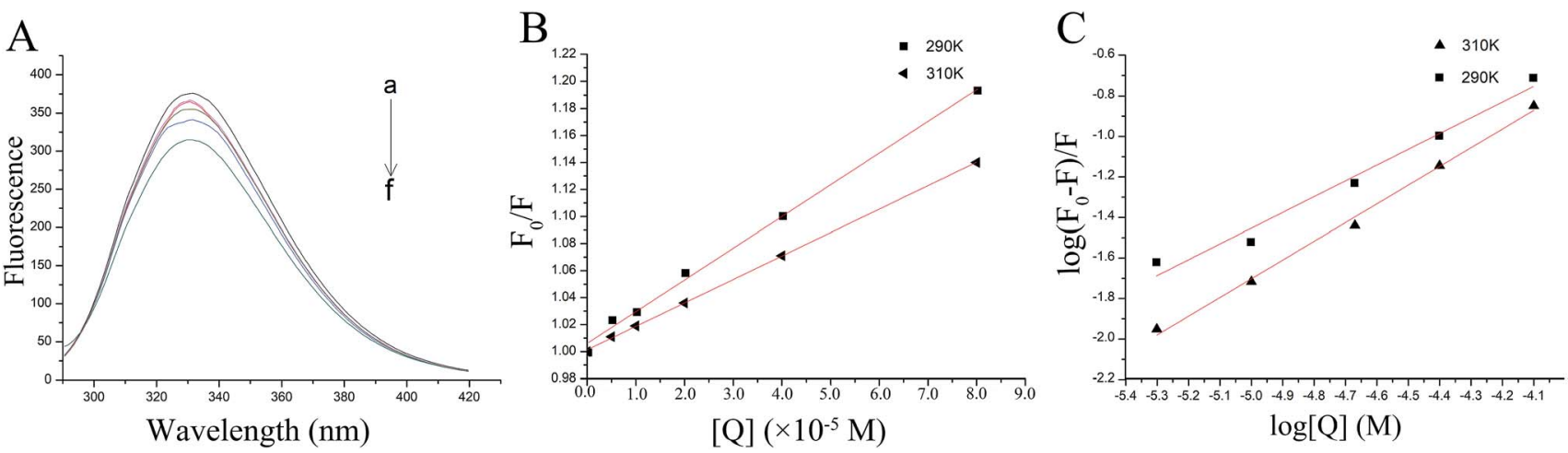

Fig. 2 The fluorescence quenching of thrombin by P10. (A) The fluorescence spectra of $5 \mu \mathrm{M}$ thrombin mixed with various concentrations of P10 $\left(\lambda_{\text {ex }}=280 \mathrm{~nm}\right)$ at $290 \mathrm{~K}$. The concentrations of P10 from "a" to "f" were 0,5 $\mu \mathrm{M}, 10 \mu \mathrm{M}, 20 \mu \mathrm{M}, 40 \mu \mathrm{M}$ and $80 \mu \mathrm{M}$. (B) The Stern-Volmer plots for the fluorescence quenching of thrombin by $\mathrm{P} 10$ at $290 \mathrm{~K}$ and $310 \mathrm{~K}$. (C) Plots of log $\left(F_{0}-F\right) / F$ against log [Q] for the P10 quenching effect on thrombin fluorescence at $290 \mathrm{~K}$ and $310 \mathrm{~K}$.

increasing temperature, indicating that the stability of the P10 plus thrombin complex decreased with increasing temperature. However, the $K_{\mathrm{b}}$ value was always in the order of $10^{2}$, indicating that the binding of P10 to thrombin was not very strong. The weak interaction between P10 and thrombin could reduce the clotting activity of thrombin to a certain extent, and was more likely to reduce the possibility of major bleeding. ${ }^{25}$ And the value of $n$ is approximately equal to 1 , indicating that the thrombin and P10 interaction is $1: 1$.

Thermodynamic parameters. Thermodynamic parameters: free energy $(G)$, standard enthalpy $(H)$ and standard entropy $(S)$ provide insight into the binding mode (including possible reactions and forces). When the temperature changes within a small range, $H$ can be considered to be a constant. The thermodynamic parameters are evaluated using eqn (3) and (4), where $R$ is the gas constant $\left(8.31 \mathrm{~K}^{-1} \mathrm{~mol}^{-1} \mathrm{~J}\right)$ and $T$ is the Kelvin temperature: ${ }^{26}$

$$
\begin{gathered}
\ln K_{\mathrm{b}}=-\frac{\Delta H}{R T}+\frac{\Delta S}{R} \\
\Delta G=\Delta H-T \Delta S=-R T \ln K_{\mathrm{b}}
\end{gathered}
$$

The values for the thermodynamic parameters interaction of P10 with thrombin are shown in Table 1. The changes in Gibb free energy $(\Delta G)<0$ indicated that the binding process of the interaction between P10 and thrombin was spontaneous. From a negative value of $\Delta H$ it can be inferred that the interaction between P10 and thrombin is an exothermic process, that is, an increase in temperature adversely affects the interaction. And $\Delta S$ was a negative value which is not favorable for the interaction of P10 with thrombin. Moreover, the bonding process was mainly due to hydrogen bonding and van der Waals forces. ${ }^{34}$

Table 1 Binding constant $K_{\mathrm{b}}$ and the relative thermodynamic parameters of the system of P10 plus thrombin

\begin{tabular}{llllll}
\hline$T(\mathrm{~K})$ & $K_{\mathrm{b}}\left(\times 10^{2} \mathrm{M}^{-1}\right)$ & $n$ & $\begin{array}{l}\Delta H \\
\left(\mathrm{~kJ} \mathrm{~mol}^{-1}\right)\end{array}$ & $\begin{array}{l}\Delta S \\
\left(\mathrm{~J} \mathrm{~mol}^{-1} \mathrm{~K}^{-1}\right)\end{array}$ & $\begin{array}{l}\Delta G \\
\left(\mathrm{~kJ} \mathrm{~mol}^{-1}\right)\end{array}$ \\
\hline \multirow{2}{*}{290} & 2.35 & 0.779 & -43.90 & -63.87 & -25.38 \\
310 & 1.74 & 0.924 & -43.90 & -63.87 & -24.10
\end{tabular}

\section{UV-vis spectroscopy study}

UV-vis absorption measurement is a simple but efficacious method to explore the structural changes of proteins and to investigate protein-ligand complex formation. ${ }^{26}$ In this study, the spectra of P10 and thrombin in the presence and absence of P10 were obtained between $185 \mathrm{~nm}$ to $400 \mathrm{~nm}$ (Fig. 3). It can be seen that thrombin has two absorption peaks at $199 \mathrm{~nm}$ and $275 \mathrm{~nm}$, respectively. By adding P10 to the thrombin solution, the peak intensities at $199 \mathrm{~nm}$ decreased with a slight blue shift $(3 \mathrm{~nm})$. And the peak at $275 \mathrm{~nm}$ basically disappeared.

In general, an absorption peak around $200 \mathrm{~nm}$ is caused by the $\pi-\pi^{*}$ transition of the $\mathrm{C}=\mathrm{O}$ group on the amide bond..$^{35}$ The interaction of P10 with thrombin caused the peptide chain of thrombin to shrink, resulting in absorbance around $200 \mathrm{~nm}$ reduction. And the addition of P10 to thrombin increases the polarity around the amide bond, resulting in an increase in the $\pi-\pi^{*}$ transition energy and a blue shift in the absorption peak. The UV absorption of the protein near the wavelength of $275 \mathrm{~nm}$ is mainly caused by the $\pi-\pi^{*}$ transition of tryptophan, tyrosine and the phenylalanine aromatic heterocycle. ${ }^{36,37} \mathrm{P} 10$ tightened the thrombin structure to mask the hydrophobic groups of

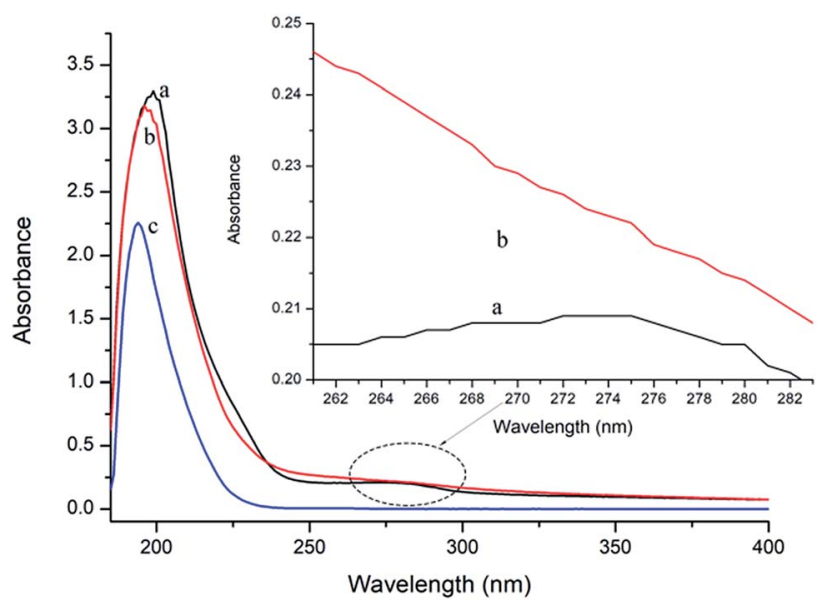

Fig. 3 UV spectra of thrombin (a), thrombin plus P10 (b) and P10 (c). The concentration of thrombin and P10 was $5 \mu \mathrm{M}$ and $80 \mu \mathrm{M}$, respectively. 
these aromatic amino acids, resulting in a weakened absorption peak. Dynamic quenching is mainly caused by the energy transfer of the receptor to the ligand by collision, and has no effect on the UV-visible spectrum of thrombin. In contrast, in static quenching, the UV-visible spectrum of the protein changes due to the complexation between the protein and the substance. $^{32}$ Thus, the change in the UV-visible spectrum showed that P10 and thrombin formed a complex and further demonstrated that the main mechanism of quenching was static quenching.

\section{CD spectroscopy study}

CD spectroscopy can measure the secondary structure of proteins in solution, such as $\alpha$-helix, $\beta$-sheet, $\beta$-turn, and random coil. The far-ultraviolet region of the $\mathrm{CD}$ spectrum in the 178-250 $\mathrm{nm}$ wavelength range is the absorption peak range of the peptide bond, reflecting the main chain conformation. ${ }^{38}$ In general, when a ligand binds to a protein, it will cause a certain change in the secondary structure of the protein. Thus, in CD spectroscopy, conformational changes in the protein caused by the ligand can be assessed by measuring the protein secondary structure. ${ }^{39}$

As shown in Fig. 4, further evidence of conformational changes in thrombin was obtained by $\mathrm{CD}$ spectroscopy at different concentrations of $\mathrm{P} 10(0,10 \mu \mathrm{M}, 40 \mu \mathrm{M}$ and $80 \mu \mathrm{M})$. The typical $\alpha$ helix structure (two negative bands centered at $208 \mathrm{~nm}$ and $222 \mathrm{~nm}$ and positive band centers near $190 \mathrm{~nm}$ ) was not found in this figure and the significant negative peak was at $206 \mathrm{~nm} .^{32}$ This was similar to the $\gamma$-thrombin structure described previously which was an interesting model for studying the conformation of thrombin activity. ${ }^{40}$ Although $\gamma$-thrombin has only $0.1 \%$ of $\alpha$ thrombin activity, it can form a clot at high enzyme concentrations. Moreover, the interaction of the ligand with $\gamma$-thrombin also reflects the interaction of the ligand with $\alpha$-thrombin to some extent. ${ }^{41}$ And the spectra showed that $\mathrm{P} 10$ resulted in an increase in the intensity of the negative peak of thrombin at $206 \mathrm{~nm}$ with a slight shift to longer wavelengths. The ratio of each secondary

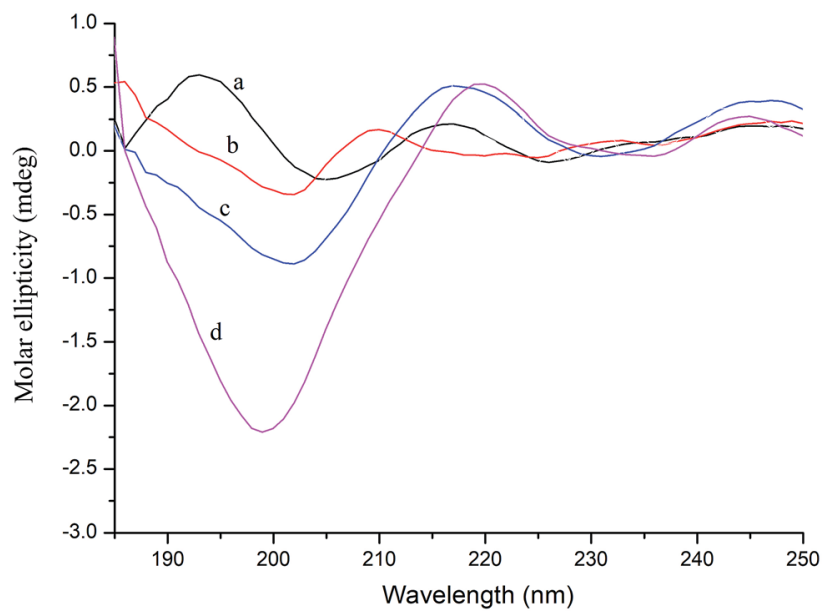

Fig. $4 \mathrm{CD}$ spectra of thrombin (a), thrombin plus $10 \mu \mathrm{M}$ P10 (b), thrombin plus $40 \mu \mathrm{M}$ P10 (c) and thrombin plus $80 \mu \mathrm{M}$ P10 (d). All of the concentrations of thrombin were $5 \mu \mathrm{M}$. structure was calculated by the Yang et al. method $^{42}$ in Table 2. The main secondary structure in this thrombin was $\beta$-sheet, accounting for $82.9 \%$. As the amount of P10 increased, the $\beta$-sheet in the enzyme decreased and the random coil content increased. This suggested that the interaction of P10 with thrombin resulted in a change in the secondary structure of thrombin.

The natural conformation as well as the specific functional domains is important for the activity of the enzyme. ${ }^{43}$ Loop ( $\beta$ turn and random coil) is a very flexible conformation. As the loop content increases, there is more chance of moving to the active center or the bonding site. Thus, these sites that are binding to the substrate are covered, resulting in the failure of the substrate to bind to the enzyme, and ultimately the enzyme is inactivated. ${ }^{\mathbf{4 4}}$ P10 increases the structure of the loop structure by interacting with thrombin molecules and changes the conformation of the thrombin molecule. Therefore, from a characterization point of view, the clotting activity of thrombin decreases as the amount of P10 increases. However, with the amount of P10 added from 0 to $80 \mu \mathrm{M}$, the change in the secondary structure of thrombin from $\beta$ sheet to random coil was only $3.8 \%$, indicating that there still was a weak force between thrombin and P10.

\section{FT-IR spectroscopy analysis}

Fig. 5 shows the characteristics of the thrombin infrared spectrum with and without the P10. There was no significant change in the main infrared absorption spectrum of thrombin with the presence of P10, but some characteristic peaks have changed.

The absorption peak of amide A usually appears at $3400 \mathrm{~cm}^{-1}$ to $3440 \mathrm{~cm}^{-1}$, and when it is associated with the hydrogen bond, it will shift to a lower wave number. ${ }^{45}$ It can be seen that the wave number of thrombin was from $3358.68 \mathrm{~cm}^{-1}$ to $3353.88 \mathrm{~cm}^{-1}$ with the addition of the P10. This was most likely due to the hydrogen bonding force between P10 and thrombin, which caused association between molecules, causing the absorption frequency of the amine group to move in the low wave direction. Moreover, it was in agreement with the previous fluorescence analysis that one of the forces between P10 and thrombin was hydrogen bonding. ${ }^{45}$ The asymmetric stretching vibration of the $\mathrm{CH}_{2}$ of amide $\mathrm{B}$ had a weak absorption at $2930.04 \mathrm{~cm}^{-1}$, and shifted the peak to $2934.19 \mathrm{~cm}^{-1}$ with the addition of P10. It indicated that P10 interfered with the asymmetric stretching vibration of $\mathrm{CH}_{2}$ of thrombin.

The peak displacement between $1600 \mathrm{~cm}^{-1}$ and $1700 \mathrm{~cm}^{-1}$ is the $\mathrm{C}=\mathrm{O}$ stretching vibration of the protein polypeptide skeleton, which is a sensitive region for the change of the secondary

Table 2 Contents of the secondary structure of thrombin treated with different concentrations of P10

\begin{tabular}{lllll}
\hline Sample & $\alpha$-Helix & $\beta$-Sheet & $\beta$-Turn & Random coil \\
\hline $\begin{array}{l}\text { Thrombin } \\
\text { Thrombin plus } 10 \mu \mathrm{M}\end{array}$ & 0 & 82.9 & 0 & 17.1 \\
$\begin{array}{l}\text { P10 } \\
\text { Thrombin plus } 40 \mu \mathrm{M}\end{array}$ & 0 & 82.5 & 0 & 17.5 \\
$\begin{array}{l}\text { P10 } \\
\text { Thrombin plus } 80 \mu \mathrm{M}\end{array}$ & 0 & 79.1 & 0 & 20.9 \\
P10 & & & &
\end{tabular}




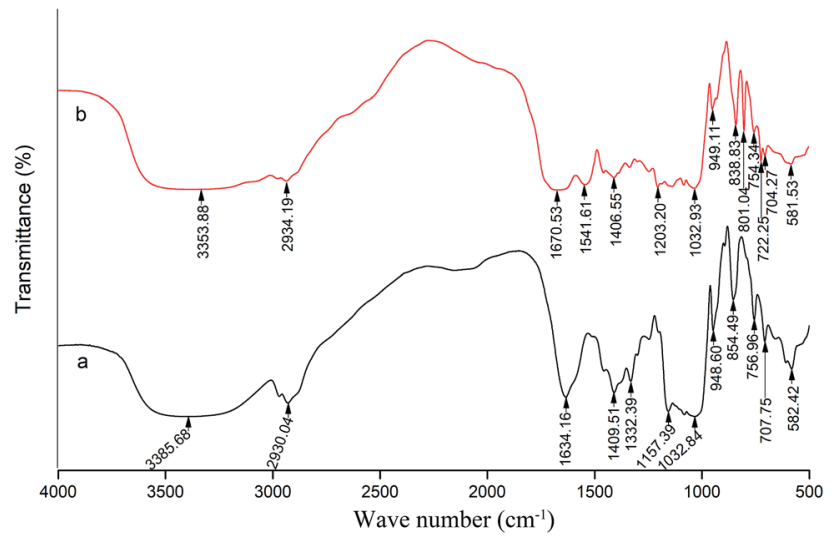

Fig. 5 FT-IR spectra of thrombin (a) and thrombin plus $80 \mu \mathrm{M}$ P10 (b). Both of the concentrations of thrombin were $5 \mu \mathrm{M}$.

structure of the protein. ${ }^{46}$ The typical absorption area of the protein secondary structure is identified as follows: 1646$1661 \mathrm{~cm}^{-1}$ is $\alpha$-helix, $1615-1637 \mathrm{~cm}^{-1}$ and $1682-1698 \mathrm{~cm}^{-1}$ is $\beta$ sheet, $1661-1681 \mathrm{~cm}^{-1}$ is $\beta$-turn, and $1637-1645 \mathrm{~cm}^{-1}$ is random coil. ${ }^{46}$ The peak of thrombin at $1634.16 \mathrm{~cm}^{-1}$ was moved to the longer wave at $1670.53 \mathrm{~cm}^{-1}$ in the presence of P10. Obviously, this showed that P10 could destroy the $\beta$-sheet of thrombin, which was the same as the CD spectroscopy result.

The band between $1200-1360 \mathrm{~cm}^{-1}$ is amide III, which is caused by $\mathrm{C}-\mathrm{N}$ stretching and $\mathrm{N}-\mathrm{H}$ bending. Also, the $\mathrm{CH}_{2}$ rocking vibration peak of glycine and proline side chain is in this region..$^{47}$ In thrombin, the characteristic frequency of the proline side chain $\mathrm{CH}_{2}$ swayed at $1332.39 \mathrm{~cm}^{-1}$. When $\mathrm{P} 10$ was added, the characteristic peak disappeared, indicating that P10 might interact with proline. In addition, the peak at $1157.39 \mathrm{~cm}^{-1}$ disappeared and the peak of $1203.32 \mathrm{~cm}^{-1}$ appeared, indicating that the $\mathrm{C}-\mathrm{O}$ stretch was affected by $\mathrm{P} 10$.

When the wave number is less than $1000 \mathrm{~cm}^{-1}$, it is mainly $\mathrm{C}-\mathrm{H}$ out-of-plane bending. The absorption peaks in this area are dense and complex. ${ }^{48}$ The wave number of $854.49 \mathrm{~cm}^{-1}$, $756.96 \mathrm{~cm}^{-1}, 707.75 \mathrm{~cm}^{-1}$ and $582.42 \mathrm{~cm}^{-1}$ shifted to $838.83 \mathrm{~cm}^{-1}, 754.34 \mathrm{~cm}^{-1}, 704.27 \mathrm{~cm}^{-1}$ and $581.53 \mathrm{~cm}^{-1}$ by adding P10, respectively. These wave numbers had undergone short-wave displacement to varying degrees, indicating the change of the $\mathrm{C}-\mathrm{H}$ microenvironment when the P10 interacted with thrombin.

\section{Raman spectroscopy}

Fig. 6 is the Raman spectra of thrombin and thrombin plus 80 $\mu \mathrm{M}$ P10. Raman spectroscopy mainly comes from the vibration of the molecular chain or side chain of the biomacromolecule. Similar to the infrared spectrum, however, the strong band generally appearing in the infrared spectrum becomes a weak band or even does not appear in the Raman spectrum. The secondary structure or conformational change are determined by analyzing the position and intensity of the amide bond. ${ }^{49}$

Thrombin had proline characteristic peaks at $450 \mathrm{~cm}^{-1}$, $494 \mathrm{~cm}^{-1}, 853 \mathrm{~cm}^{-1}$ and $931 \mathrm{~cm}^{-1}$ (Fig. 6). After the addition of P10, the intensity of these characteristic peaks was significantly reduced without significant displacement. This clarified that P10

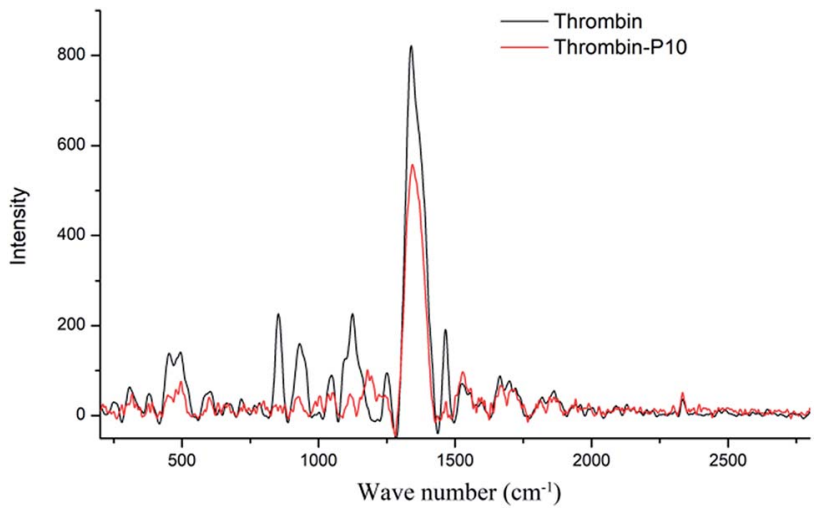

Fig. 6 Raman spectra of thrombin and thrombin plus $80 \mu \mathrm{M}$ P10. Both of the concentrations of thrombin were $5 \mu \mathrm{M}$.

had only a weak interaction with proline and did not affect the microenvironment. ${ }^{50} 1048 \mathrm{~cm}^{-1}$ and $1124 \mathrm{~cm}^{-1}$ were $\mathrm{NH}_{2}$ rocking/ twisting vibrations. After P10 interacted with thrombin, the characteristic absorption decreased at $1048 \mathrm{~cm}^{-1}$ and $1124 \mathrm{~cm}^{-1}$, but a new peak appeared at $1189 \mathrm{~cm}^{-1}$. The possible reason is that P10 binds to the side chain $\mathrm{NH}_{2}$ of the thrombin, which affects its characteristic absorption. The Raman at $1251 \mathrm{~cm}^{-1}$ was attributed to the amide III band, which is due to the peptide bond $\mathrm{C}-\mathrm{N}$ stretching and $\mathrm{N}-\mathrm{H}$ bending vibration, $\mathrm{C}_{\alpha}-\mathrm{C}$ stretching and $\mathrm{C}=\mathrm{O}$ in-plane bending. ${ }^{51}$ The decrease in the intensity of P10-thrombin in this band indicated a decrease in the degree of $\beta$-sheet folding of thrombin. This further validated the results of the previous $\mathrm{CD}$ and IR. In addition, the strong intensity absorption peak of thrombin at $1339 \mathrm{~cm}^{-1}$ was decreased in the presence of P10 and was slightly shifted to long waves $\left(1346 \mathrm{~cm}^{-1}\right)$. This indicated that P10 interacted with part of the thrombin side chain $\mathrm{CH}_{2}$ or $\mathrm{CH}_{3}$ and affected the surrounding microenvironment. ${ }^{51}$ The thrombin lysine side chain $\mathrm{C}-\mathrm{H}$ vibration caused a characteristic peak at $1465 \mathrm{~cm}^{-1}$. And the intensity of the peak at this point was significantly reduced when the P10 was combined with lysine..$^{52}$

\section{Experimental}

\section{Materials}

The P10 (Scheme 1) was synthesized by Shanghai Bootech Bioscience \& Technology Co., Ltd. (Shanghai, China) with high purity $(\geq 95 \%)$. Bovine fibrinogen and thrombin (40-300 NIH units per mg protein) were purchased from Sigma-Aldrich Co. (St. Louis, MO, USA). All the chemical reagents used were analytical grade unless indicated otherwise. The water used in this experiment was double distilled water.

\section{Determination of the antithrombotic activity}

Antithrombotic activity was determined according to the method of Yang et al. ${ }^{53}$ The samples of thrombin and fibrinogen were dissolved in $0.05 \mathrm{M} \mathrm{pH} \mathrm{7.4} \mathrm{Tris-HCl} \mathrm{buffer,} \mathrm{respectively.} \mathrm{The}$ determination was carried out using the IMark plate reader (Ujishi, Kyoto, Japan) at $405 \mathrm{~nm} .140 \mu \mathrm{L}$ of $1 \mathrm{mg} \mathrm{mL}^{-1}$ fibrinogen and $40 \mu \mathrm{L}$ of the sample were added to the microplate, then mixed and the absorbance was recorded as $S_{\mathrm{b}}$. After, $10 \mu \mathrm{L}$ of thrombin 
<smiles>C[C@H](N)C(=O)NCC(=O)N[C@@H](Cc1ccccc1)C(=O)N[C@@H](C)C(=O)NCC(=O)N[C@@H](CC(=O)O)C(=O)N[C@@H](CC(=O)O)C(=O)N[C@@H](C)C(=O)N1CCC[C@H]1C(=O)N[C@@H](CCCNC(=N)N)C(=O)O</smiles>

Scheme 1 The chemical structure of the synthesized peptide P10 (AGFAGDDAPR). The image obtained by ChemDraw.

(12 $\mathrm{IU} \mathrm{mL}^{-1}$ ) was added to the mixture which was maintained at $37^{\circ} \mathrm{C}$ for $10 \mathrm{~min}$, and the absorbance was recorded as $\mathrm{S} .40 \mu \mathrm{L}$ of buffer instead of the sample was used for control group, and the absorbances were $C_{\mathrm{b}}$ and $C$, respectively. The antithrombotic activity was calculated from eqn (5) as follows:

$$
\text { Antithrombotic activity }(\%)=\frac{\left(C-C_{\mathrm{b}}\right)-\left(S-S_{\mathrm{b}}\right)}{C-C_{\mathrm{b}}} \times 100
$$

\section{Fluorescence spectrometry}

The fluorescence spectra were recorded on the Hitachi F-4500 fluorescence spectrophotometer (Hitachi, Japan). $1 \mathrm{~mL}$ of different concentrations of P10 $(0,5 \mu \mathrm{M}, 10 \mu \mathrm{M}, 20 \mu \mathrm{M}, 40 \mu \mathrm{M}$ and $80 \mu \mathrm{M})$ and $2 \mathrm{~mL}$ of thrombin $(5 \mu \mathrm{M})$ were mixed and incubated for $10 \mathrm{~min}$ at $310 \mathrm{~K}$ and $290 \mathrm{~K}$, respectively. The fluorescence emission spectrum of the mixture from $290 \mathrm{~nm}$ to $420 \mathrm{~nm}$ was scanned, and the excitation wavelength was set to $280 \mathrm{~nm}$. The excitation and emission slit width was set to $5 \mathrm{~nm}$.

\section{UV-vis spectrometry}

The UV-vis absorption spectroscopy was determined by a UV2600 spectrophotometer (Shimadzu, Japan). The UV-vis absorption spectra of thrombin and the P10-thrombin mixtures were obtained at room temperature in the range of 185-400 nm. The concentrations of thrombin and peptide were $5 \mu \mathrm{M}$ and $80 \mu \mathrm{M}$, respectively. ${ }^{54,55}$

\section{CD spectra}

The CD spectra of the samples in the range of 185-250 $\mathrm{nm}$ were recorded on a JASCO J-810 automatic recording spectropolarimeter (Tokyo, Japan) controlled by the Jasco software with a $1 \mathrm{~cm}$ quartz cell at room temperature. In the samples, the concentration of thrombin was $5 \mu \mathrm{M}$, and the concentrations of P10 were 0, $10 \mu \mathrm{M}, 40 \mu \mathrm{M}$ and $80 \mu \mathrm{M}$, respectively. Each sample was scanned three times to find the average for a CD spectrum.

\section{FT-IR spectroscopy}

FT-IR spectroscopy analysis was carried out using a Fouriertransform infrared spectroscopy analyzer (Thermo, Massachusetts, USA). Thrombin and thrombin plus $80 \mu \mathrm{M}$ P10 were freeze-dried to obtain dry powders and separately finely ground with $\mathrm{KBr}$ to form transparent sheets. The scanning range was $500-4000 \mathrm{~cm}^{-1}$ and the resolution was $4 \mathrm{~cm}^{-1}$.

\section{Raman spectroscopy}

The measurements were carried out using a QE-Pro spectrometer (Ocean Optics, USA) with a laser source wavelength of $785 \mathrm{~nm}$ and a power of $320 \mathrm{~mW}$. The molar ratio of thrombin and P10 was $1: 16$ in the thrombin plus P10. The measurement range was $800-2870 \mathrm{~cm}^{-1}$ with scanning 2 times and the acquisition time was $25 \mathrm{~s}$.

\section{Statistical analysis}

The data was analyzed using IBM SPSS software 22.0 (IBM, Chicago, IL, USA). The chart data was smoothed and analyzed using OriginPro 8 SR4 software (OriginLab Co., Northampton, USA).

\section{Conclusions}

Spectroscopic analysis is a simple and effective method to study the interaction between small molecules and proteins. All spectroscopy results indicated that P10 can interact effectively with thrombin. P10 was primarily bound by hydrogen bonding and van der Waals forces with thrombin in a $1: 1$ ratio. The binding of P10 to thrombin was an exothermic process and produced static fluorescence quenching. In the secondary structure, P10 reduced the $\beta$-sheet structure of thrombin and transformed it into random coils. P10 bound to proline and lysine of thrombin. Therefore, P10 changes the structure of thrombin, resulting in a decrease in its enzymatic activity.

However, in the fluorescence quenching experiments, timeresolved fluorescence studies (measurement of fluorescence lifetime) are more reliable than temperature-dependent studies to distinguish between static and dynamic quenching mechanisms that can be used to further explore the interaction of thrombin and modified P10. And we cannot visually obtain 
a model of P10 and thrombin binding. This requires an auxiliary computer to simulate molecular docking to obtain a docking model. In future studies, it is necessary to conduct in vitro or in vivo experiments to verify the effectiveness of P10 in antithrombotics and lay the foundation for clinical applications.

\section{Conflicts of interest}

There are no conflicts to declare.

\section{Acknowledgements}

This work was financially supported by the Science and Technology Project of Zhejiang Province, China [grant number LGN19C200018].

\section{Notes and references}

1 A. A. Syed and A. Mehta, Int. J. Pept. Res. Ther., 2018, 24, 1-12. 2 J. Xiao, R. L. Melvin and F. R. Salsbury, J. Biomol. Struct. Dyn., 2018, 37, 982-999.

3 S. J. Degen, R. T. Macgillivray and E. W. Davie, Biochemistry, 1983, 22, 2087-2097.

4 R. J. Butkowski, J. Elion, M. R. Downing and K. G. Mann, J. Biol. Chem., 1977, 252, 4942-4957.

5 W. Bode, D. Turk and A. Karshikov, Protein Sci., 1992, 1, 426471.

6 F. V. De, L. Acquasaliente, G. Pontarollo and D. Peterle, Biotechnol. Appl. Biochem., 2018, 65, 69-80.

7 L. Acquasaliente, D. Peterle, S. Tescari, N. Pozzi and V. D. Filippis, Biochem. J., 2016, 473, 4629-4650.

8 P. E. Bock, P. Panizzi and I. M. Verhamme, J. Thromb. Haemostasis, 2010, 5, 81-94.

9 L. Stefano, R. Sergio, D. F. Vincenzo, P. Nicola, R. Bianca and D. C. Raimondo, J. Biol. Chem., 2008, 283, 30193-30204.

10 J. Venkatesan, S. Anil, S. K. Kim and M. S. Shim, Mar. Drugs, 2017, 15, 143-161.

11 E. H. H. Husein and R. F. Castillo, J. Cosmet. Dermatol., 2016, 15, 514-519.

12 L. Waxman, D. E. Smith, K. E. Arcuri and G. P. Vlasuk, Science, 1990, 248, 593-596.

13 A. Z. Fernandez, A. Tablante, S. Beguín, H. C. Hemker and R. Apitz-Castro, Biochim. Biophys. Acta, Protein Struct. Mol. Enzymol., 1999, 1434, 135-142.

14 W. Gan, D. Li, Y. Chen, Q. He, J. He, Y. Huan, J. Xian, C. Lu, Y. Wu and L. Peng, FEBS Lett., 2009, 583, 1976-1980.

15 B. Zhao, Y. Zhang, Y. Huang, J. Yu, Y. Li, Q. Wang, Y. Ma, H. Song, M. Yu and W. Mo, Thromb. Haemostasis, 2017, 117, 44-56.

16 Z. Zhang, Z. Li, J. Li and L. Liu, Sci. Rep., 2018, 8, 8847.

17 M. Tu, L. Feng, Z. Wang, M. Qiao, F. Shahidi, W. Lu and M. Du, J. Funct. Foods, 2017, 32, 313-323.

18 A. Biela, F. Sielaff, F. Terwesten, A. Heine, T. Steinmetzer and G. Klebe, J. Med. Chem., 2012, 55, 6094-6110.

19 M. Qiao, M. Tu, H. Chen, F. Mao, C. Yu and M. Du, Int. J. Mol. Sci., 2018, 19, 2100-2112.

20 J. Nauś, Biol. Plant., 1996, 38, 620.
21 E. Kristiani, L. H. Nugroho, S. Moeljopawiro and S. Widyarini, AIP Conf. Proc., 2016, 1744, 1-7.

22 Y. Ren, H. Wu, F. Lai, M. Yang, X. Li and Y. Tang, Food Res. Int., 2014, 64, 931-938.

23 S. Zhang, Food Chem., 2016, 202, 1-8.

24 L. Feng, M. Tu, M. Qiao, F. Fan, H. Chen, W. Song and M. Du, Eur. Food Res. Technol., 2018, 244, 207-217.

25 M. Gou, L. Wang and X. Liu, Nat. Prod. Res., 2017, 31, 11681171.

26 T. Chen, S. Zhu, H. Cao, Y. Shang, M. Wang, G. Jiang, Y. Shi and T. Lu, Spectrochim. Acta, Part A, 2011, 78, 1295-1301.

27 H. Zhao, Q. Wei, Z. Ning, E. Yuan and L. Chen, Sci. Technol. Food Ind., 2012, 33, 53-55.

28 A. S. Ladokhin, Fluorescence Spectroscopy in Peptide and Protein Analysis, 2006.

29 D. M. Charbonneau and T. R. Heidar-Ali, J. Phys. Chem. B, 2010, 114, 1148-1155.

30 M. G. Galinato, R. S. Fogle 3rd and J. F. Galan, Spectrochim. Acta, Part A, 2013, 115, 337-344.

31 K. Kuijpers, C. Bottecchia, D. Cambie, K. Drummen, N. Koenig and T. Noel, Angew. Chem., Int. Ed., 2018, 57, 11278-11282.

32 B. H. M. Hussein, J. Lumin., 2011, 131, 900-908.

33 A. Belatik, S. Hotchandani, J. Bariyanga and H. A. TajmirRiahi, Eur. J. Med. Chem., 2012, 48, 114-123.

34 P. D. Ross and S. Subramanian, Biochemistry, 1981, 20, 30963102.

35 M. C. Yoon, Y. S. Choi and K. K. Sang, Chem. Phys. Lett., 1999, 300, 207-212.

36 Z. Chi, R. Liu and Y. Teng, J. Agric. Food Chem., 2010, 58, 10262-10269.

37 Z. Zhang, C. Feng, D. Dong, Z. Chen, S. Zang, X. Su, B. Geng and G. Zhao, Acta Chim. Sin., 2006, 64, 953-958.

38 J. M. Hierrezuelo, B. Nieto-Ortega and C. Carnero Ruiz, J. Lumin., 2014, 147, 15-22.

39 Q. Wang, J. He, D. Wu, J. Wang, J. Yan and H. Li, J. Lumin., 2015, 164, 81-85.

40 G. B. Villanueva, Biochemistry, 1981, 20, 6519-6525.

41 T. L. Chang, R. D. Feinman, B. H. Landis and J. W. Fenton, Biochemistry, 1979, 18, 113-119.

42 J. T. Yang, C. S. C. Wu and H. M. Martinez, Methods Enzymol., 1986, 130, 208-269.

43 Y. H. Chen, J. T. Yang and H. M. Martinez, Biochemistry, 1972, 11, 4120-4131.

44 Q. Shen, B. Huang, J. Shao, Q. Peng, L. Ma and L. Gu, Acta Sci. Nat. Univ. Pekin., 2006, 45, 62-64.

45 J. H. Muyonga, C. G. B. Cole and K. G. Duodu, Food Chem., 2004, 86, 325-332.

46 K. J. Payne and A. Veis, Biopolymers, 1988, 27, 1749-1760.

47 M. Jackson, L. P. Choo, P. H. Watson, W. C. Halliday and H. H. Mantsch, Biochim. Biophys. Acta, 1995, 1270, 1-6.

48 Q. Wan, M. Dang, J. Zeng, L. Chun-Mei and H. Zhao, Food Sci., 2009, 30, 28-31.

49 R. S. Das and Y. K. Agrawal, Vib. Spectrosc., 2011, 57, 163176. 
50 M. Guilbert, G. Said, T. Happillon, V. Untereiner, R. Garnotel, P. Jeannesson and G. D. Sockalingum, Biochim. Biophys. Acta, Gen. Subj., 2013, 1830, 3525-3531.

51 N. Ignatieva, O. Zakharkina, G. Leroy, E. Sobol, N. Vorobieva and S. Mordon, Laser Phys. Lett., 2007, 4, 749-753.

52 G. Zhu, X. Zhu, Q. Fan and X. Wan, Spectrochim. Acta, Part A, 2011, 78, 1187-1195.
53 W. Yang, Z. Wang and S. Xu, Chin. Chem. Lett., 2007, 18, 449451.

54 A. J. Esfahlan and V. P. Azar, Food Chem., 2016, 202, 426-431. 55 Y. Wang, H. Zhang, G. Zhang, W. Tao and S. Tang, J. Lumin., 2007, 126, 211-218. 